\title{
Implementation of a custom-made mouthguard in a professional basketball team
}

\author{
Moreira, A*, Mendes, J**, Fonte, E* , Ferreira, D***, Clemente, $\mathrm{M}^{*}$, \\ Vasconcelos, $\mathrm{M}^{* * * * *}$
}

\author{
*Faculty of Dental Medicine, University of Porto, andre.luis.sa.moreira@gmail.com (A.M.); estelle.fonte@gmail.coml (E.F.); \\ miguelpaisclemente@hotmail.com (M.C.); R. Dr.Manuel Pereira da Silva; Porto;Portugal \\ ** Department of Mechanics, Faculty of Engineering, University of Porto, jgabriel@fe.up.pt,4200-465 Porto, Portugal \\ *** Instituto Universitário Egas Moniz, danielgcmferreira@gmail.com, 2829-511, Lisboa, Portugal. \\ **** Faculty of Dental Medicine, University of Porto, mvasconcelos@fmd.up.pt@fmd.up.pt, R. Dr.Manuel Pereira da Silva; Porto ;Portugal.
}

\begin{abstract}
Introduction: Orofacial trauma related with sports happens both in organized or amateur situations. Taking into consideration the group of sports that are collective and of contact, basketball is undoubtedly a sport with a moderate risk of orofacial trauma. Mouthguards can be a preventive measure to reduce the incidence and severity of orofacial trauma, if they are used during sports practice when indicated. Basketball is a sport with a moderate risk to orofacial trauma and the use of mouthguards is still rare in it.
\end{abstract}

Objective: The aim of this investigation is to study a professional basketball team's receptivity to and acceptance of the use of mouthguards during their practices.

Materials and Methods: It was assessed the expectations and opinions of 13 basketball players of Futebol Clube Porto team before and after the use of a custom-made mouthguard. The custom-made mouthguard was produced by the Erkoform 3D Motionwith the Occluform-3 accessory using 2 plaques of ethyl vinyl acetate, $4 \mathrm{~mm}$ and $2 \mathrm{~mm}$ thickness.

Results: Only one player had used a mouthguard before. There was a change for a better opinion in 'adaptation' and 'retention' which showed statistically significant differences before and after the use of the custom-made mouthguard, $p=0,045$ and $p=0,025$ respectively. Breathing, communication and salivation didn't show any statistically significant differences. About $76.9 \%$ of the players would recommend the use of the testedcustom-made mouthguard for playing basketball.

Conclusions: The use of mouthguard should be mandatory to play basketball and a custom-made mouthguard may be well accepted in the Portuguese basketball population. DOI: https://doi.org/10.24243/JMEB/3.4.195 $\underline{\text { Research Article }}$

Recommended by Associate Editors Elza M. Fonseca 


\section{Introduction}

Sports activity is starting to be part of our daily routine, the physical well-being walks aside the psychological and social well-being [1].With the increase of sports practice rises the risk of lesions, although the statistic values vary, dental and orofacial lesions are very common. The result of this kind of lesion can certainly affect the performance and career of an athlete. Above all, the orofacial and dental trauma may affect the personal life of an athlete [2], [3]. Dental trauma have an incidence between 25 to $30 \%$ on the sports population, according Glendor et al., 2009 [4]. Orofacial trauma (OT) related with sports happens both in organized or amateur situations. Apparently, these type of lesions are more frequent in team sports and happens with more severity in individual sports. Taking in consideration the group of sports that are collective and of contact, basketball is undoubtedly a sport with a moderate risk to orofacial trauma. It's considered by Azodo et al. 2011 as the sport with most frequently dental emergencies in children and teenagers [1], [3], [5], [6].Basketball is considered one of the most dynamic sport during all the game-time. Over 40 minutes the athletes must have a wide range of basic and specific skills, not only physical, but also functional. The game is dominated by the explosive power, coordination of specific and physical tasks, spatial orientation, agility to deal with new situations, speed reaction of the neuromuscular complex and consequently quick moves [1]. Mouthguards can be a preventive measure to reduce the incidence and severity of OT, if mouthguards are used during the sports practice when indicated [7]. The use of mouthguards is recommended by the American Dental Association since 1950. Mouthguard is defined as a resilient device applicable to the mouth with the aim to prevent and reduce OT [8]-[10]. It offers protection separating the cheeks and the lips from the teeth, making the users less susceptible to soft tissue lacerations, preventing the both dental arches to contact traumatically and protecting particularly the teeth, as also the other involving structures. This appliance acts by absorbing and dissipating the forces from the impact/blow [2], [10]-[13]. Such sports where the use of mouthguard is mandatory have shown a decrease of $60 \%$ in the number of dental lesions [14].

According to Jerolimov et al. 2010, there are 3 classes of mouthguards: extra-oral, intradental and combined. The extra-oral are a kind of mouthguard fixed to a helmet. The intradental have 3 different types. Type I: standard/stock mouthguard that can be acquired in different colors and sizes. They are ready-made and used as such. They are made of rubber or polyvinyl chloride. However, they are the least efficient; Type II: boil-and-bite or mouthformed mouthguards they adapt to the mouth after having been softened by heating in water; Type III: custom-made mouthguard which offers the best protection. They are fabricated in dental offices or laboratories to ensure a harmonized relationship with the dental arch, better absorption and distribution of forces [2], [8], [10]-[12].

The aim of this investigation is to study the admission and receptivity of a professional basketball team to the use of mouthguards during their practices. It will be study a single bran of custom-made mouthguard made from two plaques with different thicknesses of ethyl vinyl acetate (EVA). Posteriorly to the distribution of the custom-made mouthguards, at the end of 10 basketball practices with the duration of 90 minutes each athlete will full-fill a survey. From the survey it will be assessed the breathing, phonation, esthetic, muscle pain, comfort felt, adaptability and retention. We strongly believe it is necessary to go through this matter, once basketball is a sport with a moderate risk to orofacial trauma and the use of mouthguards is still rare in [15].

\section{Methodology}

The study population in this investigation was the Futebol Clube do Porto's (FCP) basketball team. In the first encountering it was full-filled the first part of the survey: consent form, identification of the player and player characteristics, history of the use of mouthguard and history of orofacial trauma. It was impressed the upper and lower arch with Zhermack orthoprint alginate and it was register the occlusion-bite, with the silicone Ventura Bite. Lately, from the impressions, using stone gypsum type III Madespa, it was obtained the casts. Finally, before sending the casts to the laboratory, they were prepared to be able to articulate between the upper and lower model together with the silicone occlusion-bite register. In the dental laboratory, it was used the Erkoform 3D Motion machine with the Occluform-3 accessory and two plaques of EVA with $4 \mathrm{~mm}$ and $2 \mathrm{~mm}$ of thickness, both with $120 \mathrm{~mm}$ of diameter(Figure 1). Firstly, it was placed the upper cast in the recipient, stabilized by the granules, with the occlusion surface up faced. Secondly, it was selected the termoformation program for the first lamination of the $2 \mathrm{~mm}$ thickness plaque, which had a temperature of $130^{\circ} \mathrm{C}$ and a time of cooldown of 3 minutes. Finished and cut the first lamination, it was thermoformed the second layer of EVA with $4 \mathrm{~mm}$ thickness. Before the second lamination, the Occluform-3 


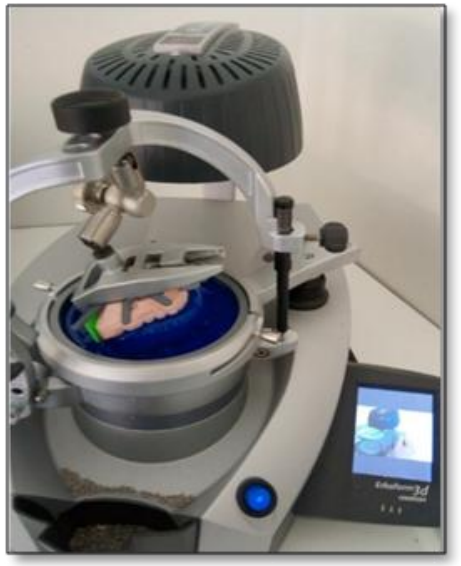

a)

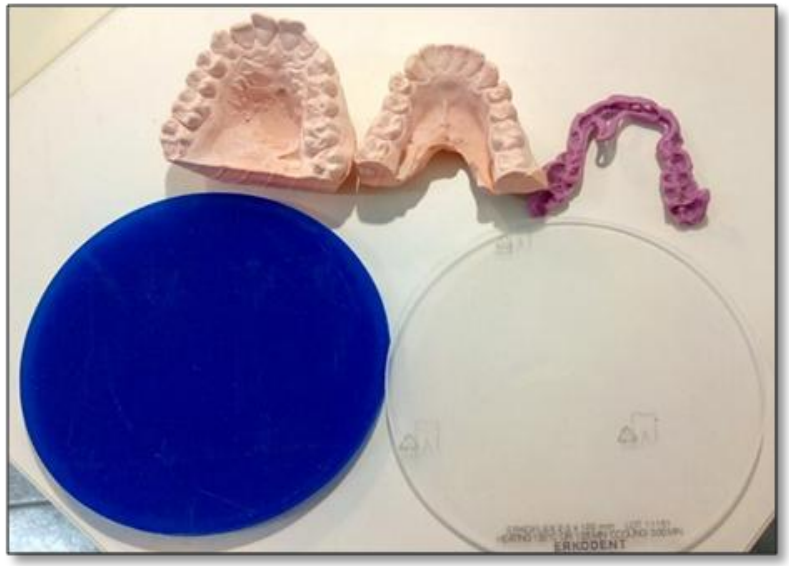

b)

Fig.1 (a) Erkoform 3dMotion - thermoforming the second lamination; (b) Two plaques of EVA with 4mm and 2mm of thickness, both with 120mm of diameter, upper and lower model and occlusal bite registration

accessory was prepared by setting up the lower cast supported by the occlusion-bite register. One more time, it was selected the correct termoformation program, this time for a plaque of $4 \mathrm{~mm}$ thickness, which had a temperature of $100^{\circ} \mathrm{C}$ and a time of cooldown of 6 minutes. In the recipient we had the upper cast with the first layer/laminate adapted and cropped, ready to receive the second plaque of $4 \mathrm{~mm}$ thickness. Immediately after the second laminate termoformation, during the cooldown, the lower cast was occluded with the upper cast, allowing to register the athlete stable occlusion-bite on the mouthguard. Then, it was cut the excess of EVA at frenulum's, vestibule and labial area. It was polished with a micromotor and softened with a Bunsen burner. On the second encountering with the basketball F.C.Porto team, the 13 custom-made mouthguards were delivered together with the second part of the survey(Figure 2). After 10 basketball practices of 90 minutes, the athletes full-filled the second part of the survey about the changes on the athlete's performance that might have been felt during the practices due to the mouthguard, their subjective appreciation of the mouthguard and if they would recommend it or not. We used SPSS Statistics version 24.0 (Statistical Package for the Social Sciences) to analyze the data. Taking in consideration the necessary criteria to realize the parametric tests, we concluded that the sample did not follow a normal distribution in the variables studied. Thus, it was used a non-parametric test, Wilcoxon test. Wilcoxon test for a population's median is the non-parametric test used when it is intended to compare the measure of central tendency of the studied population with a theoretic value [16].

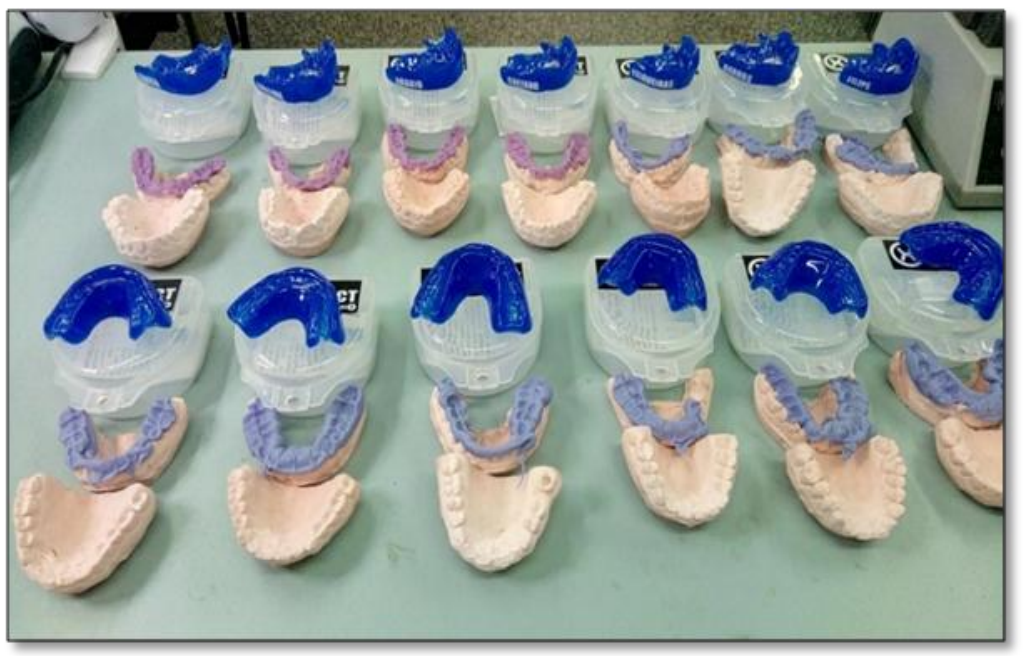

a)

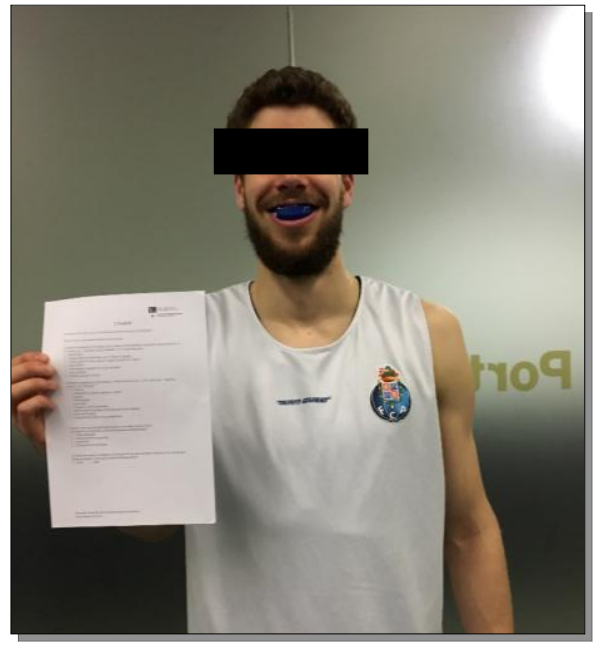

b)

Fig.2. a) 13 custom-made mouthguards ready for delivery; b) F.C.P. athlete with the second part of the survey and already using the mouthguard. 
The basketball team was composed by 13 male athletes with the age between 17 to 23 years old. They have been practice basketball for an average of 10.3 years per athlete, with a minimum of 7 years and a maximum of 13 years of practice. Regarding the athlete game-position there were:

- $\quad 23.1 \%(\mathrm{n}=3)$ playing as Point guard;

- $\quad 30.8 \%(n=4)$ playing as Shooting guard;

- $\quad 30.8 \%(n=4)$ playing as Small forward;

- $\quad 15.4 \%(n=2)$ playing as Power forward;

The average of international competitions by player was $18.8(\mathrm{n}=13)$, by having registered a minimum of 1 and a maximum of 50 international competitions. About 30.8\% $(n=4)$ of the players reported having suffered an OT in the past, where none of the players were using mouthguard in the moment of the incident. From the OT reported, two of them where soft tissue lacerations, one a dental fracture and the other a maxillary trauma. Only one player had used a mouthguard before, a mouthguard type III (custom-made). The basketball risk for an OT was classified with two modes, of 6 and 7, in a scale from 1 to 10 (being 1 the minimum risk and 10 the maximum risk). About 61.5\% (n=8) believed that the game-position of a player influenced the risk of the same player having an OT. All the 13 athletes, at the momentum of the survey, knew already what a mouthguard was for. About $46.2 \%(n=6)$ have heard about the mouthguard from the "Team", 38.5\% from the "Television" and $15.4(\mathrm{n}=2)$ from the "Dentist". In relation to the reasons why the athletes never have used a mouthguard before, we found the following modes $(n=13)($ Table 1$)$ :

Table 1 - First survey with the reasons why the players didn't use a mouthguard, classified in a scale from 1 to 10, being 1 the most preponderant and 10 the less preponderant;

\begin{tabular}{ll}
\hline Variable & Mode \\
\hline Never have suffered an orofacial trauma before & 1 \\
Difficulty communicating during the game & 3 and 5 \\
Difficulty breathing & 8 \\
\hline Lack of retention & 5 and 7 \\
\hline Improper adaptation of the device to the mouth & 3 \\
\hline Caused a decrease on the saliva production (thirst sensation) & 6 and 7 \\
\hline Esthetics reasons & 10 \\
\hline Difficulty acquiring a mouthguard & 9 \\
\hline Economic reasons & 10 \\
\hline Not being mandatory the use of a mouthguard to the sport practice & 2 and 8 \\
\hline
\end{tabular}

After the use of our custom-made mouthguard, we found the following results regarding the changes felt by the athletes during the basketball practices due to the use of the mouthguard (Table 2):

Table 2 - Second survey results about the player's feedback on the changes they may have felt on their performance due to the use of the mouthguard; Scale from 1 to 10, where 1 means "Almost not affected" and 10 means "Very affected";

\begin{tabular}{ll}
\hline Variable & Mode \\
\hline Breathing & 3 \\
Capacity in communicating with the team colleagues & 8 \\
Decrease in the salivary flow & 3 \\
\hline Bad breath & 1 \\
\hline Changes in the gingiva and/or gingiva pain & 2 \\
\hline Dental pain & 1 \\
\hline Fascial muscle pain & 1 \\
\hline
\end{tabular}


Thus, the following evaluation was classified from 1 to 10 , having the number 1 the meaning of "Very little" and the number 10 the meaning of "Very high" (Table 3 ):

Table 3 - Second survey results about the evaluation made by the players on the custom-made mouthguard characteristics;

\begin{tabular}{ll}
\hline Variable & Mode \\
\hline Comfort & 3 \\
Adaptation to the teeth, gingiva and palate & 8 \\
Rigidity & 8 \\
\hline Flexibility & 4 \\
\hline Softness & 7 \\
\hline Visible wear/tear on the mouthguard & 3 \\
\hline Deformation of the mouthguard (changes in the original & 7 \\
form) & 7 and 8 \\
Level of protection felt & 1 \\
Changes in the game performance & \\
\hline
\end{tabular}

Regarding the appreciation felt for the mouthguards by the athletes, 10 of them responded "Appreciated", 2 "Moderately appreciated" and only one "Not appreciated". In the end, 10 of the 13 athletes would recommend the custom-made mouthguard to be used constantly and continuously in basketball practice. When we compared the player's opinion on the analyzed criteria, before the use and after the use of the mouthguard, we found statistically significant difference to "Adaptation" and "Retention", with a p of 0.025 and 0.045 , respectively $(\mathrm{p}<\alpha(0.05))$. To the other criteria, such as, "Communication", "Breathing" and "Salivation", it was not found any statically significant difference, $\mathrm{p}=0.141, \mathrm{p}=0.916$ and $\mathrm{p}=0.751$ respectively (Table 4).

Table 4 - Wilcoxon test to compare the change of the player's opinion on a custom-made mouthguard;

\begin{tabular}{lll}
\hline Parameters & $\mathrm{Z}$ & $\begin{array}{l}\text { Significance } \\
\text { (Bilateral) }\end{array}$ \\
\hline Communication.After - Communication.Before & -1.474 & 0.141 \\
Breathing.After - Breathing.Before & -0.106 & 0.916 \\
Retention.After - Retention.Before & -2.007 & 0.045 \\
Adaptation.After - Adaptation.Before & -2.247 & 0.025 \\
Salivation.After - Salivation.Before & -0.318 & 0.751 \\
\hline
\end{tabular}

\section{Discussions}

Our study respected the concept that the average thickness of a custom mouthguard is $4 \mathrm{~mm}$. This $4 \mathrm{~mm}$ thickness provides sufficient protection and comfort during the use [17]-[19]. Previous studies have demonstrated that there is an inverse proportion between the thickness of the mouthguard and the shock absorption capacities [17]. However, increasing the thickness will inevitably lead to less comfort and negative effects on the physiological stomatognathic system [20]. When the thickness is more than $6 \mathrm{~mm}$, discomfort, respiratory problems and a poor acceptance of the mouthguard are more likely [21]. The idea that a mouthguard will affect breathing capacity during sports activities, also as, the communication capacity is still going on. Our results have shown no statically significant differences to the parameters communication, breathing and salivating. We can affirm that what the team was expecting from a mouthguard didn't change positively or negatively after the use of a custom-made mouthguard. However, we should have in count that communication was the parameter less appreciated by our 13 athletes. This discomfort has already been reported in other studies, athletes normally feel difficulty communicating, when they apply a mouthguard during their sports activities [11], [13], [22]. The belief that mouthguards are most of times bulky, have a bad-adaptation to the mouth and are uncomfortable have risen due to the use of stock and boil-\&-bite mouthguards [11], [13]. Custom-made mouthguards have been proven to be significantly superior to type I and type II 
mouthguards [23]-[26]. DeYoung et al., 1994, compared the comfort of custom-made and boil and bite mouthguards and conclude that besides more comfortable, there were higher adverse effects on the stomatognathic system functions when standard mouthguards are used [27]. Identical results were found by Gawlak et al., 2016, when they compared 5 different types of mouthguards. Their study provided clear evidence at a standard mouthguard, particularly Porida mouthguard, could trigger mucosal irritations, sores and difficulty in breathing [28]. Some athletes already know that a custom made mouthguard is the best option to reduce the risk of OT, but in many instances price determines which mouthguard is used [24]. In the present study, such as in other studies where it was tested a custom-mouthguard, shows that the custom-mouthguard do not affect the athletes performance during practices or competitions, can be well adapted and comfortable [13], [22]. The athletes' expectations to the parameters adaptation and comfort were statistically different to those parameters, $(\mathrm{p}(0.045)<\alpha=0.05)$ and $(\mathrm{p}(0.025)<\alpha=0.05)$ respectively. This found means that the tested custom-mouthguard was better than what the athletes were expecting to be regarding those parameters. Eroglu et al., 2006, also showed in a tae know do population that a custom-made mouthguards were well accepted by elite tae know do athletes in terms ability to breathe, ease fitting into the mouth, stability and overall satisfaction [29]. No adverse effect to the health of the athlete were found, such as, bad breath, changes in the gingiva or gingival pain, teeth pain, fascial muscle pain. We can allege that a properly done custom-mouthguard has almost none inconvenient to the athletes' performance, same thing was proposed previously by other authors [13], [30], [31]. Although, it must be taken into account that a custom mouthguard with 5 years old or more, may lose the initial properties what can cause a less effective appliance in the event of an impact. Furthermore, after years of use it may also fit improperly due to teeth movement, worn down or even restored [24]. Ultimately, we found a positive receptivity from the F.C.Porto's professional basketball team to the tested custom-mouthguard. About 76,9\% (10/13) answered "Appreciated" to our bran of mouthguards and the same number would recommend it and advocate the continuous use of it during basketball practices and competitions. In addition to professional athletes also amateur athletes and children should wear a mouthguard while participating in sports that pose an orofacial injury risk [4]. The stock mouthguard, type I, is the less adapted, less comfortable, it lacks retention so the athlete needs to clench his teeth to hold the mouthguard in the maxilla which may lead to masticatory mialgia. On the other hand, can be easily found and it's cheaper. The boil-and-bite mouthguard, type II, is a better alternative for amateur athletes and children than type I, it's easy to find and can be home made. Because children's orofacial structures may be growing and year after year a new mouthguard should be done, the small investment is well apply for their protection [11], [13]. The boil-and-bite, although better than the standard mouthguard, falls short compared to the custom-made mouthguard. The custom-made mouthguard, type III, is the goldstandard for orofacial trauma protection. Thus, adult professional athletes should look for this type of mouthguard to obtain a great performance with an excellent preventive intraoral device. Although, the custom-made mouthguard is more expensive than the other two types of mouthguards, because it's made by a dentist completely adapted to the athletes' mouth, it's more comfortable, more retentive, is less bulky and can be personalized [10]-[12], [23]-[26].

\section{Conclusion}

The implementation of the custom-mouthguard in the F.C.Porto's professional basketball team showed to exceed the expectancies of the athletes with statically significant differences regarding the parameters retention and adaptation. Independently of not having appeared any kind of discomfort or side effect, in general the principal complain was the difficulty in communicating. Future measures should be taken regarding the manufacturing process of mouthguards to improve the athletes' ability to speak by maintain the other characteristics. We draw the attention of our professional colleagues that the Portuguese basketball athletes are a group of risk in relation to the orofacial trauma. It should be mandatory the use of a mouthguard to play basketball. Our sample showed to accept the tested custom-made mouthguard, we believe that this sport's population is receptive to the use of a custom-made mouthguard.

\begin{tabular}{ll}
\hline Nomenclature \\
\hline $\boldsymbol{O T}$ & Orofacial Trauma \\
$\boldsymbol{E V A}$ & Ethyl vinyl acetate \\
\hline
\end{tabular}




\section{Acknowledgements}

The authors would like to thank the collaboration of Dentalmaster for supporting the study with 26 plaques of ethyl-vinil-acetate and, also to thank Ximpact lab for supporting the study by confectioning the custom-made mouthguards.

\section{Funding}

The authors would like to acknowledge the support of UISPA (LAETA / INEGI) and FCT under the project FCT-UID/EMS/50022/2013.

\section{References}

[1] Lešić N, Seifert D, Jerolimov V. Orofacial injuries reported by junior and senior basketball players. Collegium antropologicum. 2011 Jun 24;35(2):347-52.

[2] Young EJ, Macias CR, Stephens L. Common dental injury Management in Athletes. Sports health. 2015 May;7(3):250-5.

[3] Dursun E, Ilarslan YD, Ozgul O, Donmez G. Prevalence of dental trauma and mouthguard awareness among weekend warrior soccer players. Journal of oral science. 2015;57(3):191-4.

[4] Spinas E, Aresu M, Giannetti L. Use of mouth guard in basketball: observational study of a group of teenagers with and without motivational reinforcement. European journal of paediatric dentistry: official journal of European Academy of Paediatric Dentistry. 2014 Dec;15(4):392-6.

[5] Frontera RR, Zanin L, Ambrosano GM, Flório FM. Orofacial trauma in Brazilian basketball players and level of information concerning trauma and mouthguards. Dental traumatology. 2011 Jun 1;27(3):208-16.

[6] Ashley P, Di Iorio A, Cole E, Tanday A, Needleman I. Oral health of elite athletes and association with performance: a systematic review. Br J Sports Med. 2015 Jan 1;49(1):14-9.

[7] Cohenca N, Roges RA, Roges R. The incidence and severity of dental trauma in intercollegiate athletes. The Journal of the American Dental Association. 2007 Aug 1;138(8):1121-6.

[8] Dhillon BS, Sood N, Sood N, Sah N, Arora D, Mahendra A. Guarding the precious smile: Incidence and prevention of injury in sports: A review. Journal of international oral health: JIOH. 2014 Jul;6(4):104.

[9] Mendel DA, Ucar Y, Brantley WA, Rashid RG, Harrell SL, Grentzer TH. Impact energy absorption of three mouthguard materials in an aqueous environment. Dental Traumatology. 2009 Feb;25(1):130-5.

[10] Ranalli DN. Sports dentistry and dental traumatology. Dental Traumatology. 2002 Oct;18(5):231-6.

[11] Ifkovits T, Kühl S, Connert T, Krastl G, Dagassan-Berndt D, Filippi A. Prevention of dental accidents in Swiss boxing clubs. Swiss dental journal. 2015;125(12):1322-35.

[12] Jerolimov V. Temporomandibularne ozljede i poremećaji u sportu. Rad Hrvatske akademije znanosti i umjetnosti: Medicinske znanosti. 2010 Apr 12(507=34):149-65.

[13] Duddy FA, Weissman J, Lee Sr RA, Paranjpe A, Johnson JD, Cohenca N. Influence of different types of mouthguards on strength and performance of collegiate athletes: a controlled-randomized trial. Dental traumatology. 2012 Aug;28(4):2637.

[14] Farrington T, Onambele-Pearson G, Taylor RL, Earl P, Winwood K. A review of facial protective equipment use in sport and the impact on injury incidence. British journal of oral and maxillofacial surgery. 2012 Apr 1;50(3):233-8.

[15] Tiryaki M, Saygi G, Yildiz SO, Yildirim Z, Erdemir U, Yucel T. Prevalence of dental injuries and awareness regarding mouthguards among basketball players and coaches. The Journal of sports medicine and physical fitness. 2017 Nov;57(11):1541-7.

[16] Marôco J. Análise Estatística com o SPSS Statistics.: $7^{\text {a }}$ edição. ReportNumber, Lda; 2018 Jun 15.

[17] Westerman B, Stringfellow PM, Eccleston JA. EVA mouthguards: how thick should they be?. Dental traumatology. 2002 Feb;18(1):24-7.

[18] Ozawa T, Takeda T, Ishigami K, Narimatsu K, Hasegawa K, Nakajima K, Noh K. Shock absorption ability of mouthguard against forceful, traumatic mandibular closure. Dental Traumatology. 2014 Jun;30(3):204-10.

[19] Yamada J, Maeda Y, Satoh H, Miura J. Anterior palatal mouthguard margin location and its effect on shock-absorbing capability. Dental Traumatology. 2006 Jun;22(3):139-44.

[20] Takeda T, Ishigami K, Handa J, Naitoh K, Kurokawa K, Shibusawa M, Nakajima K, Kawamura S. Does hard insertion and space improve shock absorption ability of mouthguard?. Dental Traumatology. 2006 Apr;22(2):77-82.

[21] Maeda M, Takeda T, Nakajima K, Shibusawa M, Kurokawa K, Shimada A, Takayama K, Ishigami K. In search of necessary mouthguard thickness. Part 1: From the viewpoint of shock absorption ability. Nihon Hotetsu Shika Gakkai Zasshi. 2008 Apr 10;52(2):211-9. 
[22] Ma W. Basketball players' experience of dental injury and awareness about mouthguard in China. Dental Traumatology. 2008 Aug;24(4):430-4.

[23] Newsome PR, Tran DC, Cooke MS. The role of the mouthguard in the prevention of sports-related dental injuries: a review. International Journal of Paediatric Dentistry. 2001 Nov;11(6):396-404.

[24] Patrick DG, Van Noort R, Found MS. Scale of protection and the various types of sports mouthguard. British journal of sports medicine. 2005 May 1;39(5):278-81.

[25] Francois A, Heyns M, Pretorius J. Shock absorption potential of different mouth guard materials. The Journal of prosthetic dentistry. 1999 Sep 1;82(3):301-6.

[26] Badel T, Jerolimov V, Pandurić J, Carek V. Custom-made mouthguards and prevention of orofacial injuries in sports. Acta medica Croatica: casopis Hravatske akademije medicinskih znanosti. 2007;61:9-14.

[27] DeYoung AK, Robinson E, Godwin WC. Comparing comfort and wearability: custom-made vs. self-adapted mouthguards. Journal of the American Dental Association (1939). 1994 Aug;125(8):1112-8.

[28] Gawlak D, Mańka-Malara K, Kamiński T, Łuniewska M, Mierzwińska-Nastalska E. Comparative evaluation of custom and standard boil and bite (self-adapted) mouthguards and their effect on the functioning of the oral cavity. Dental traumatology. 2016 Oct;32(5):416-20.

[29] Eroğlu E, Diljin KA, Lütfi BM. Elite tae kwon do athletes' satisfaction with custom-made mouthguards. Dental Traumatology. 2006 Aug;22(4):193-7.

[30] Gawlak D. Evaluation of mouthguard usage by teenagers practicing various sport disciplines-initial clinical research. Czas Stomatol. 2009;62:134-41.

[31] Keçeci AD, Çetin C, Eroğlu E, Baydar ML. Do custom-made mouth guards have negative effects on aerobic performance capacity of athletes?. Dental Traumatology. 2005 Oct;21(5):276-80.

\section{Appendix}

\section{A.1. Ethical approval statement given by the President of Ethical Committee Professor António Felino from the Faculty of Dental Medicine of University of Porto (FMDUP)}

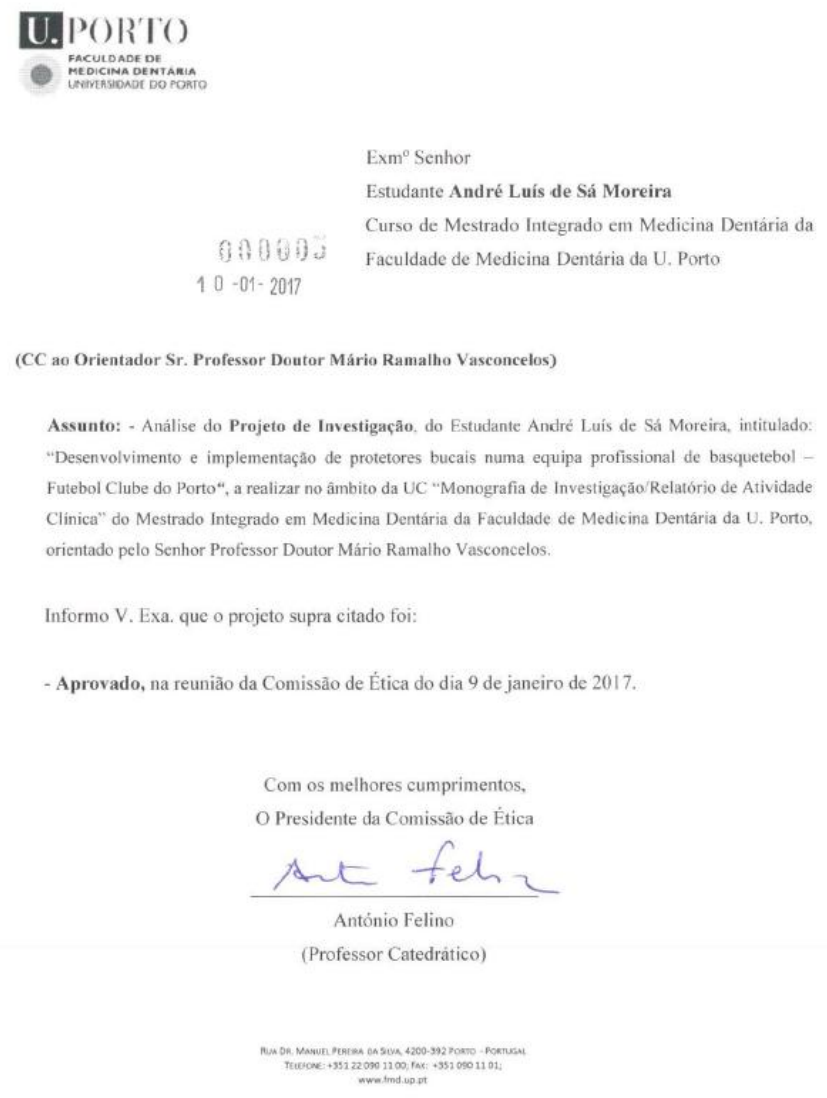

